\title{
CONSIDERAÇõES SÔBRE AMOSTRAGEM DE PEIXES MARINHOS (I)
}

(Recebido em 1/4/60)

\author{
H. Nomura*
}

CONTEÚ DO

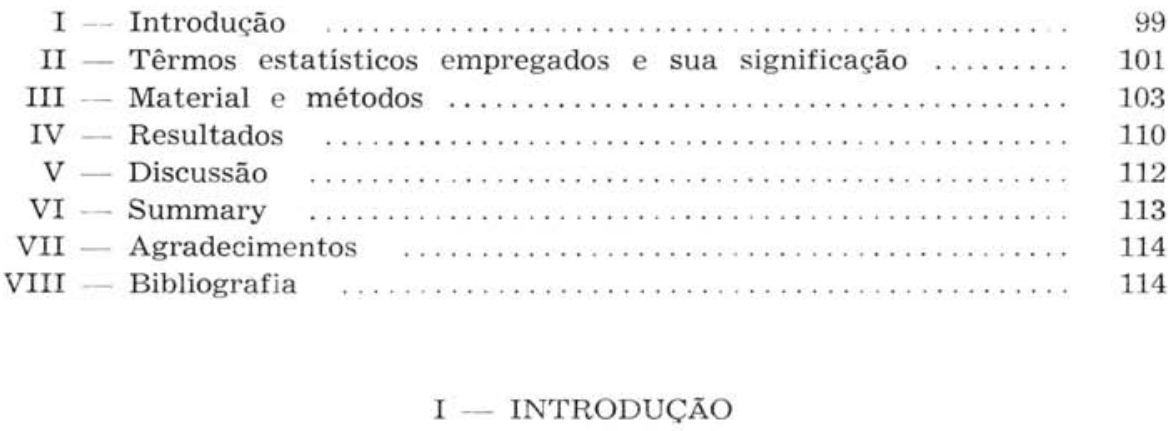

Em agôsto de 1958 teve início, na cidade de Santos, Estado de São Paulo, como parte de um programa a longo prazo destinado a avaliar os estoques de peixes existentes na costa brasileira, uma nova fase da coleta de dados relativos a várias espécies ictiológicas, de valor comercial. No momento as espécies que mais nos preocupam são: a sardinha verdadeira (Sardinella allecia [Rafinesque, 1810] Fowler, 1941)**, a corvina (Micropogon furnieri [Desmarest, 1822] Jordan, 1884), a pescada foguete ( $M a-$ crodon ancylodon [Bloch, 1801] Jordan, Evermann \& Clark, 1930), o goete (Cynoscion petranus [Ribeiro, 1915] Lara, 1948) e a mis-

* Membro do Grupo Estadual de Pesquisas sôbre a Pesca Marítima - Av. Bartolomeu de Gusmão, 192 - Santos, SP.

** Esta denominacão tem prioridade sôbre Sardinella aurita Cuv. et Val., 1847, segundo Fowler (1941).

Publ. no 125 do Inst. Ocean. da USP. 
tura, categoria que engloba as espécies acima mencionadas (exceto a sardinha verdadeira) e várias outras, que têm baixo valor comercial.

$\mathrm{Na}$ amostragem dos estoques de peixes faz-se uso da frota comercial, na suposição de que o peixe desembarcado no Entreposto reflete a composição dos estoques no mar. Esta suposição pode, ou não, estar correta. Entretanto, isso não interessa no presente trabalho, que se restringiu à melhoria das técnicas de amostragem requeridas para avaliar o peixe capturado e desembarcado no Entreposto; acha-se também restrito à avaliação da composição de comprimentos das sardinhas desembarcadas.

O peixe capturado e desembarcado durante o ano é constituído pelas capturas de muitos barcos de pesca, provenientes de épocas, locais e aparelhos de pesca diferentes. A composição de tamanho pode, portanto, variar entre barcos, entre áreas exploradas, entre estações diferentes, etc. Enquanto a magnitude das variações não fôr conhecida, é impossível a retirada eficiente de amostras representativas, de tal modo a dar uma avaliação exata do pescado desembarcado anualmente, ou por qualquer outro período. Numa viagem os barcos geralmente dão lances em diversos lugares. Mesmo que sejam capturados no mesmo bloco de pesca, na mesma hora ou em horas diferentes, os cardumes apresentam composição de comprimento variável.

Futuramente pretende-se lidar separadamente com cada variável e, finalmente, tendo em mente o problema sob consideração e o pessoal disponível, sugerir as mínimas necessidades da amostragem.

O problema ventilado neste trabalho diz respeito ao número de peixes requerido em uma amostra, que forneça um quadro representativo da população da qual a amostra é retirada. Neste caso o têrmo população significa, em todo o sentido, o produto da captura de um barco. Essa população poderá ser constituída pela captura de um, ou de vários lances, como já foi mencionado linhas atrás. Por isso devemos levar em conta os erros que poderão advir porque ignoramos se os produtos de todos os lances estão, ou não, misturados naquilo que é desembarcado no Entreposto. Outrossim, deve-se levar em consideração que as variáveis referentes a área ou tempo foram omitidas no presente trabalho.

Paralelamente à avaliação da composição de comprimentos obtêm-se amostras para o laboratório, constituídas de um certo número de exemplares. Dessas amostras determinam-se o comprimento, o pêso, o sexo, o perímetro, o grau de maturidade sexual; pêso, comprimento e volume das gônadas e realiza-se a retirada 
do estômago para exame do conteúdo estomacal. As variáveis referentes a essas amostras também serão tratadas em trabalhos futuros.

iI - TÉRMOS ESTATÍSTICOS EMPREGAdOS E SUA SIGNIFICAÇÃO

Os têrmos estatísticos utilizados neste trabalho vão definidos abaixo, baseados em trabalhos de vários autores.

Média aritmética é uma estimativa não viciada da verdadeira média dos comprimentos obtida pela análise de uma amostra ao acaso (random sample).

Desvio padrão (s) é uma medida que dá o desvio típico da média. Pela fórmula (vide Tabela I) depreende-se que provém da raiz quadrada da variância. Êste elemento estatístico serve para indicar, na assim chamada distribuição normal, que em $95 \%$ dos casos a verdadeira média da população estará compreendida no limite entre a média observada e mais, ou menos, duas vêzes $o$ desvio padrão $(\overline{\mathrm{x}} \pm 2 \mathrm{~s})$; sòmente em $5 \%$ (um em vinte) dos casos a média verdadeira estará fora dêsses limites, que são denominados limites de confiança de $95 \%$ (Gulland, 1957).

Variância $\left(\mathrm{s}^{2}\right)$ é a medida da dispersão das estimativas ao redor do seu valor médio. Êste elemento tem grande importância em Estatística. De uma caixa contendo sardinhas, por exemplo, podem-se medir 50, 100, 150, 200, 250, 300 exemplares, etc., e analisando-se essas amostras, a variância deverá ser inversamente proporcional ao tamanho delas, isto é, o aumento de tamanho da amostra deve redundar em decréscimo da variância, desde que o método de amostragem seja bom. Uma vez conhecida a variância de uma amostra, dois limites de tamanho podem ser estabelecidos: $1 .^{\circ}$ ) se o seu valor fôr muito elevado, as estimativas serão inexatas, restando abandonar o método de amostragem adotado ou aumentar o tamanho da amostra; $2 .^{\circ}$ ) o seu valor pode ser tal que as estimativas serão exatas para todos os fins semelhantes e, portanto, a tomada de amostras maiores será perda de tempo. O limite dêsse valor é estabelecido pela análise de amostras anteriores, com a aceitação de certo êrro que deve ser levado em consideração, tomando-se por base o pessoal e o tempo disponível.

Vício (bias) é a extensão pela qual o valor médio difere do verdadeiro valor. Vícios podem resultar do aparelho de pesca (deve-se conhecer suas propriedades seletivas), da amostragem 


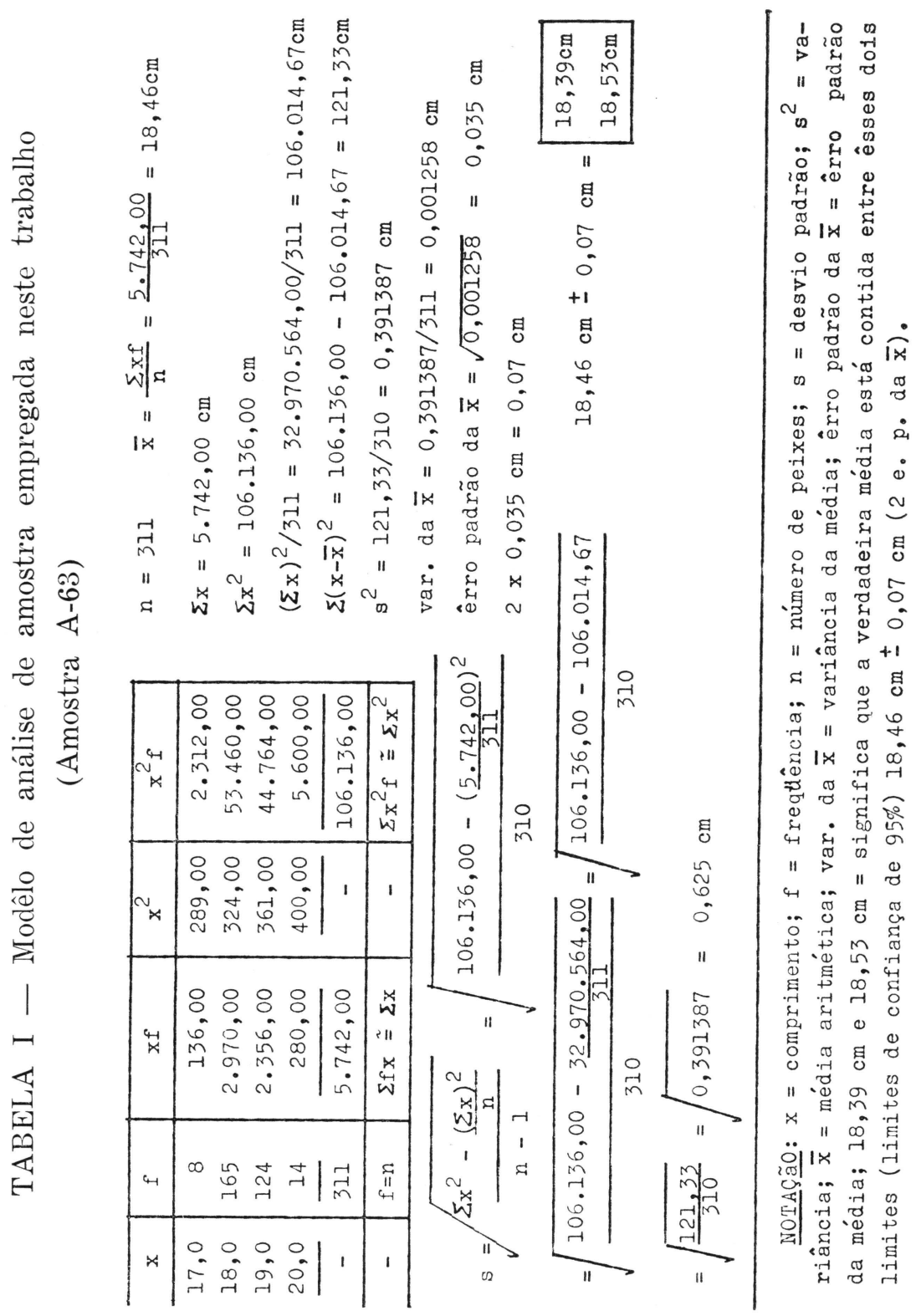


estratificada, da distribuição das amostras no tempo e no espaço, do método ineficiente de análise dos dados obtidos, dos erros pessoais de medição, da variação na composição do estoque de peixes, de acôrdo com o tempo e local, da separação de peixes por categorias de tamanho no Entreposto (ou mercado), etc.

Variância da média é a variância dividida pelo número de peixes medidos numa amostra. A exatidão da variância da média de uma amostra feita ao acaso é inversamente proporcional ao número de unidades presentes na amostra.

Êrro padrão da média é a raiz quadrada da variância da média, ou seja, uma medida da magnitude média do êrro da amostragem feita ao acaso (Pope, 1956). A verdadeira média dos comprimentos dos peixes desembarcados estará contida nos limites compreendidos entre a média obtida e, mais, ou menos, duas vêzes o êrro padrão da média $(\overline{\mathrm{x}} \pm 2 \mathrm{e}$. p. $)$, sendo que sòmente em $5 \%$ (um em vinte) dos casos ela estará fora dêsses limites.

Na Tabela II há outro têrmo, Bloco, que deve ser explicado. Cada bloco corresponde a áreas de sessenta minutos de lado e é numerado de acôrdo com as coordenadas geográficas (vide Fig. 1).

\section{III - MATERIAL E MÉTODOS}

Para o estudo do peixe desembarcado é necessário se adotar um método de amostragem. Um dos dados que se obtém com rapidez e facilidade, nos locais de desembarque, é o comprimento do peixe, com consistência de resultados, mesmo que a medição seja efetuada por diferentes pessoas.

Faz-se medição de peixes e contagem do número dêles contidos em caixas de pêso conhecido com a finalidade de se calcular o número e os comprimentos dos peixes desembarcados.

As verdadeiras estimativas poderiam ser obtidas se se medissem todos os peixes desembarcados. Entretanto, essa operação envolveria muitas pessoas e exigiria muitas horas de trabalho. Os mesmos resultados podem ser obtidos mediante a medição de parte do peixe capturado e desembarcado, fazendo-se uso do pessoal e do tempo disponível.

A sardinha é capturada por meio de uma rêde denominada traina, cuja descrição se encontra no trabalho de Vieira, Carvalho e outros (1945).

As traineiras (barcos sardinheiros) de Santos só pescam à noite e durante a lua nova. Quando há fortes tempestades, a pes- 


\begin{tabular}{|c|c|}
\hline 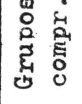 & 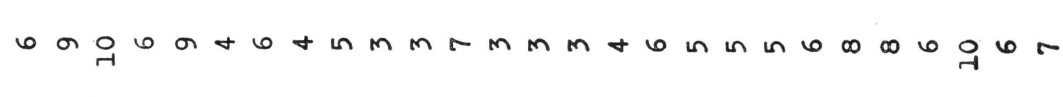 \\
\hline 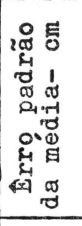 & 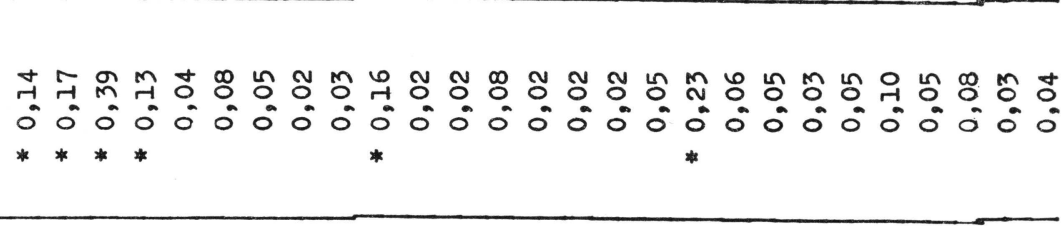 \\
\hline 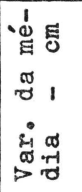 & 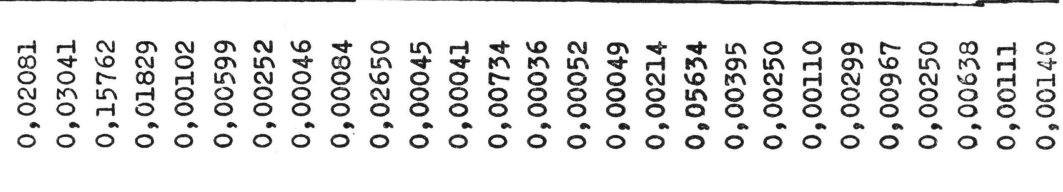 \\
\hline 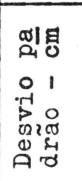 & 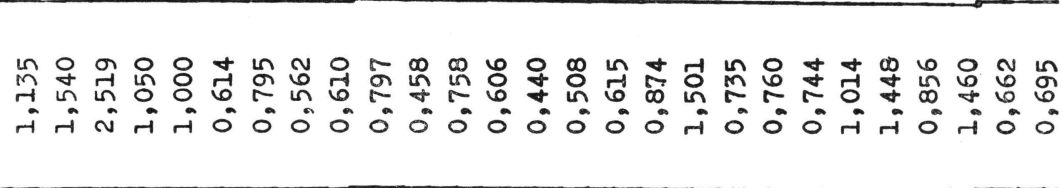 \\
\hline 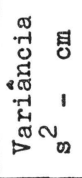 & 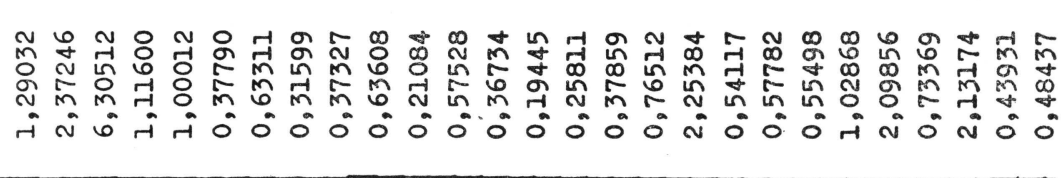 \\
\hline 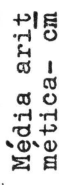 & 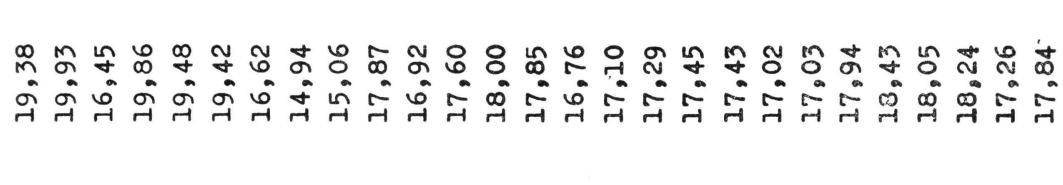 \\
\hline 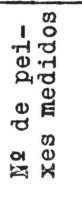 & 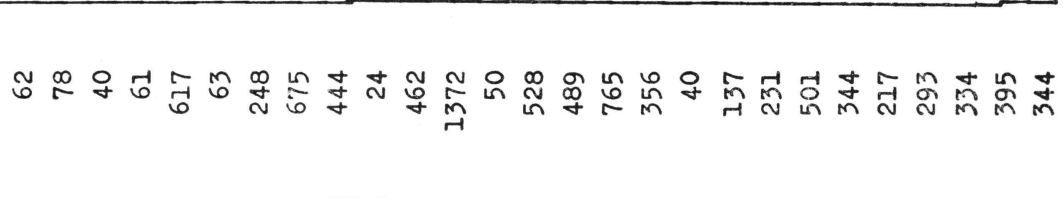 \\
\hline $\begin{array}{l}: \\
: \\
\stackrel{-1}{M}\end{array}$ & 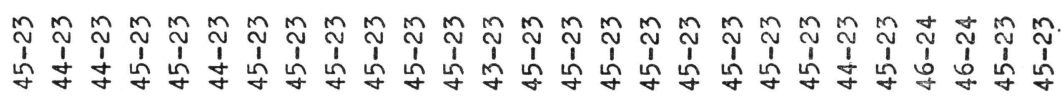 \\
\hline 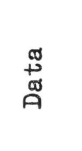 & 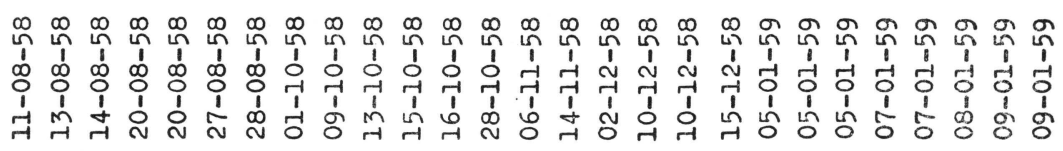 \\
\hline $\begin{array}{l}0 \\
0 \\
4 \\
0 \\
0 \\
0 \\
0 \\
0\end{array}$ & 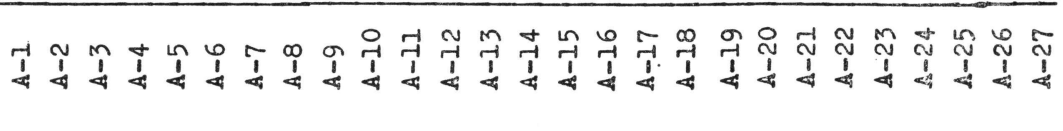 \\
\hline
\end{tabular}




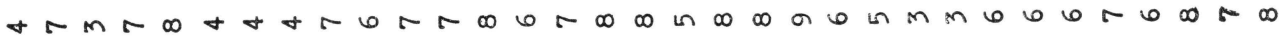

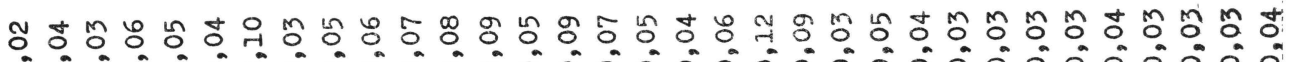

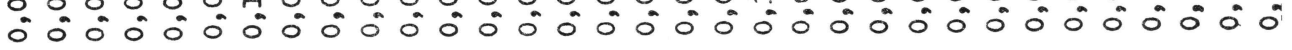

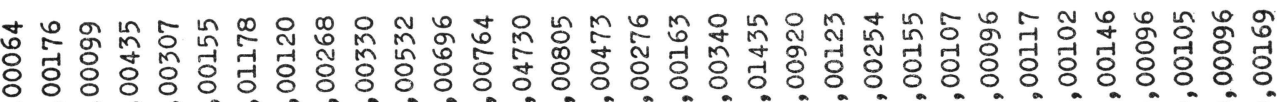
0
0

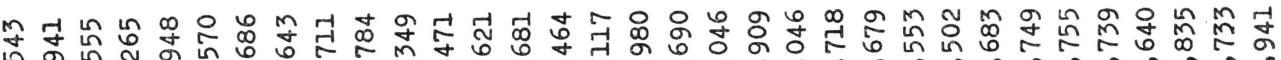

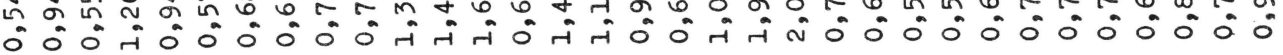

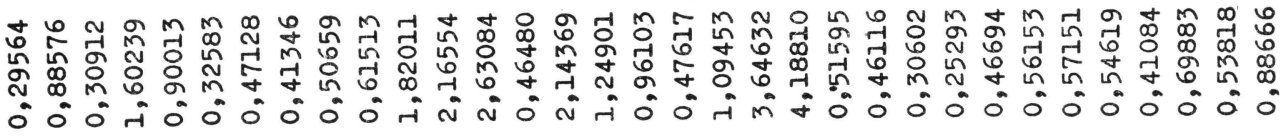

초

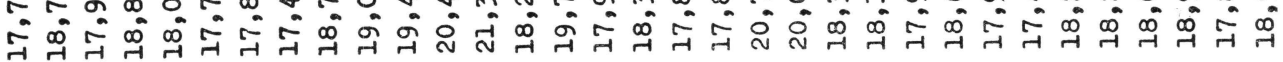

엉개

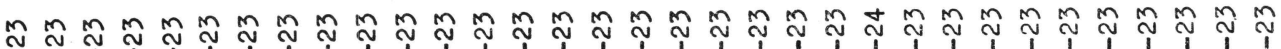

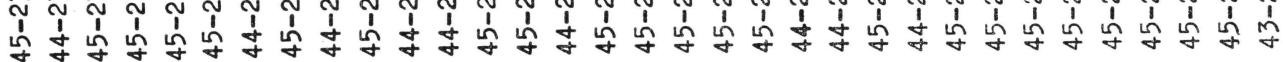

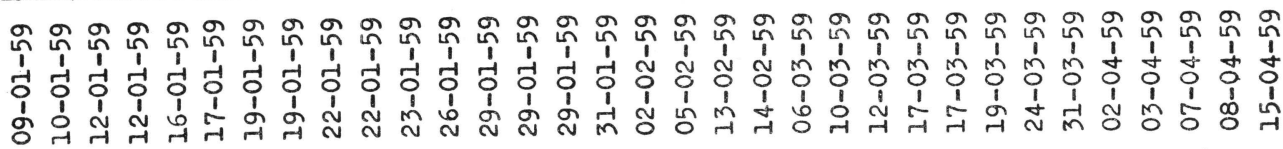

오ㅇㅠㅛ

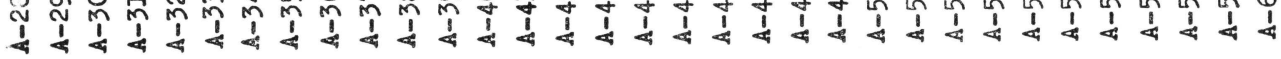




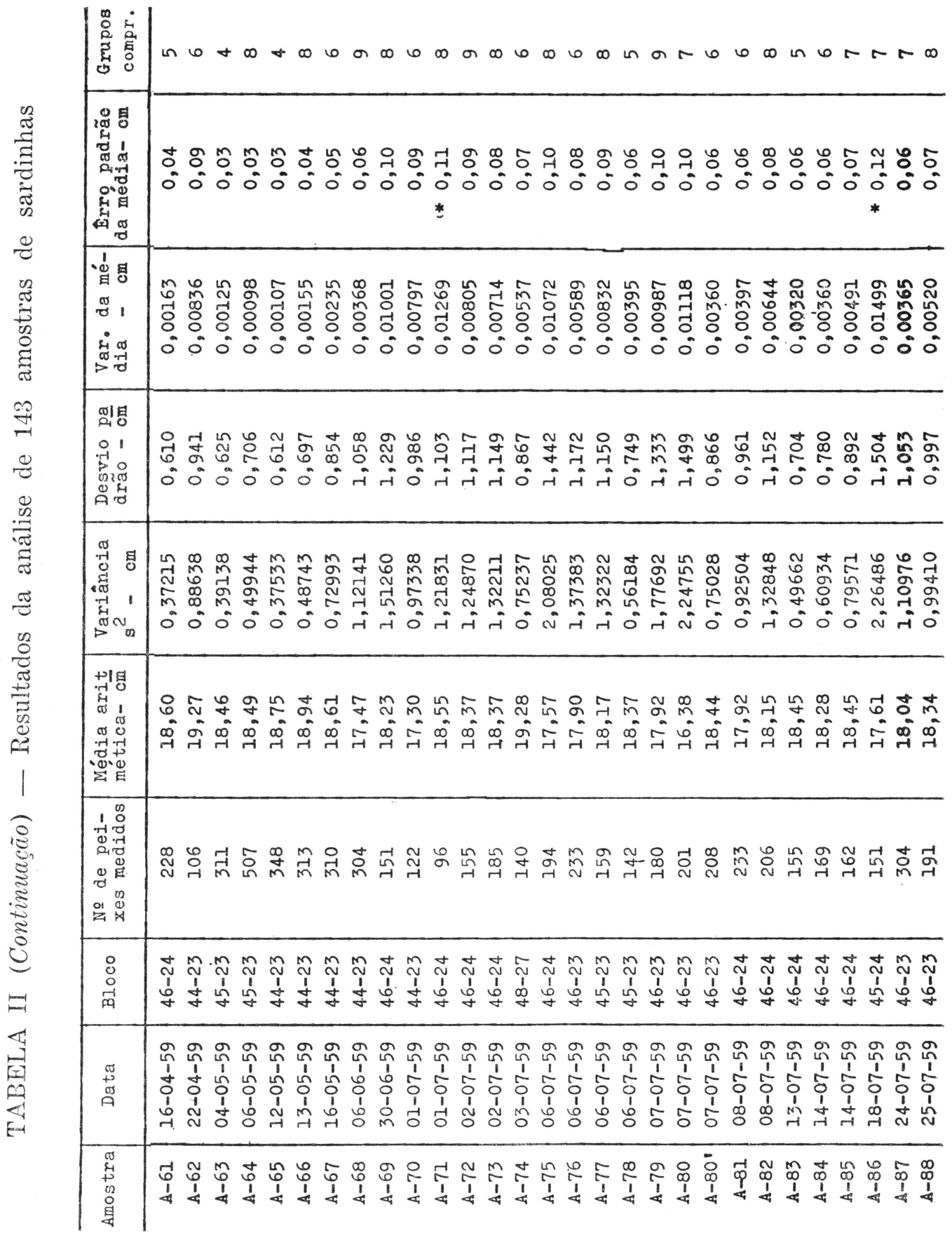


6 o 감 0 r

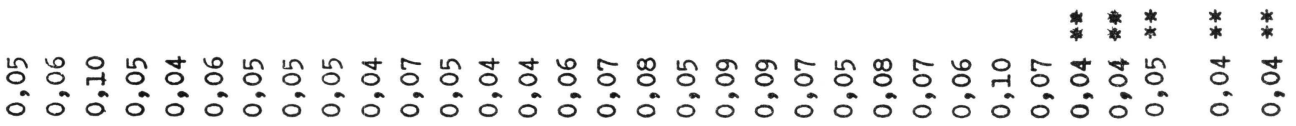

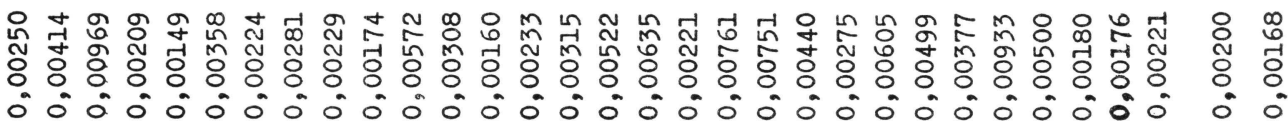

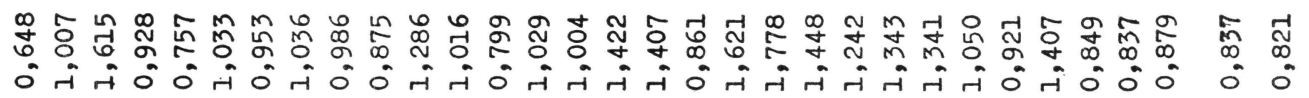

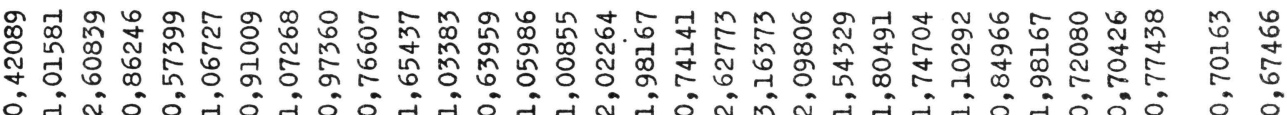

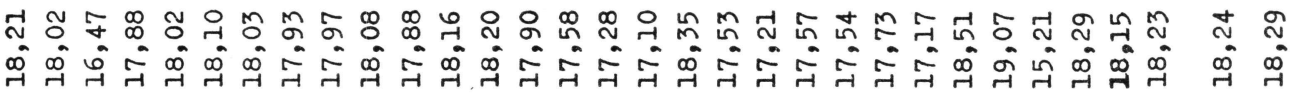

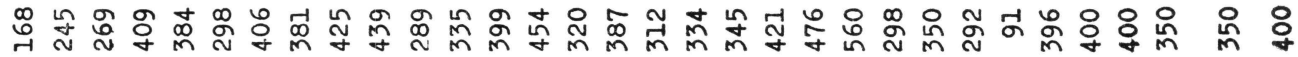

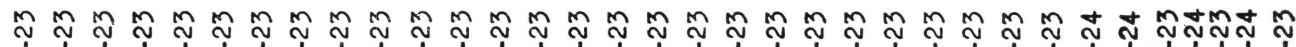

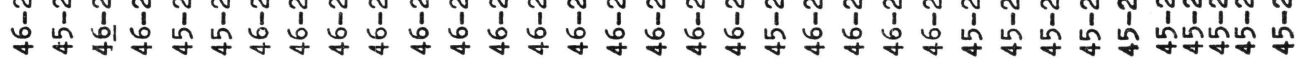

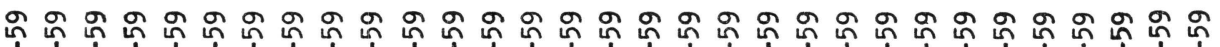

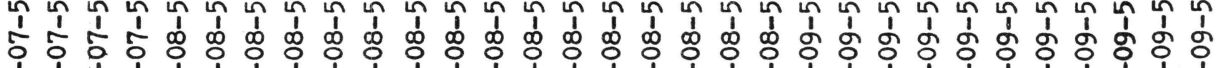

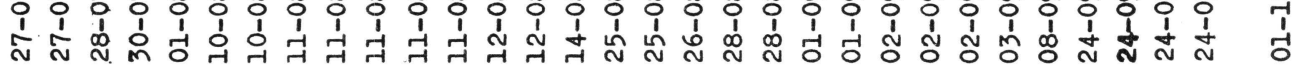

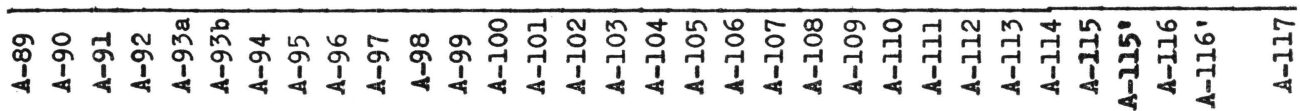




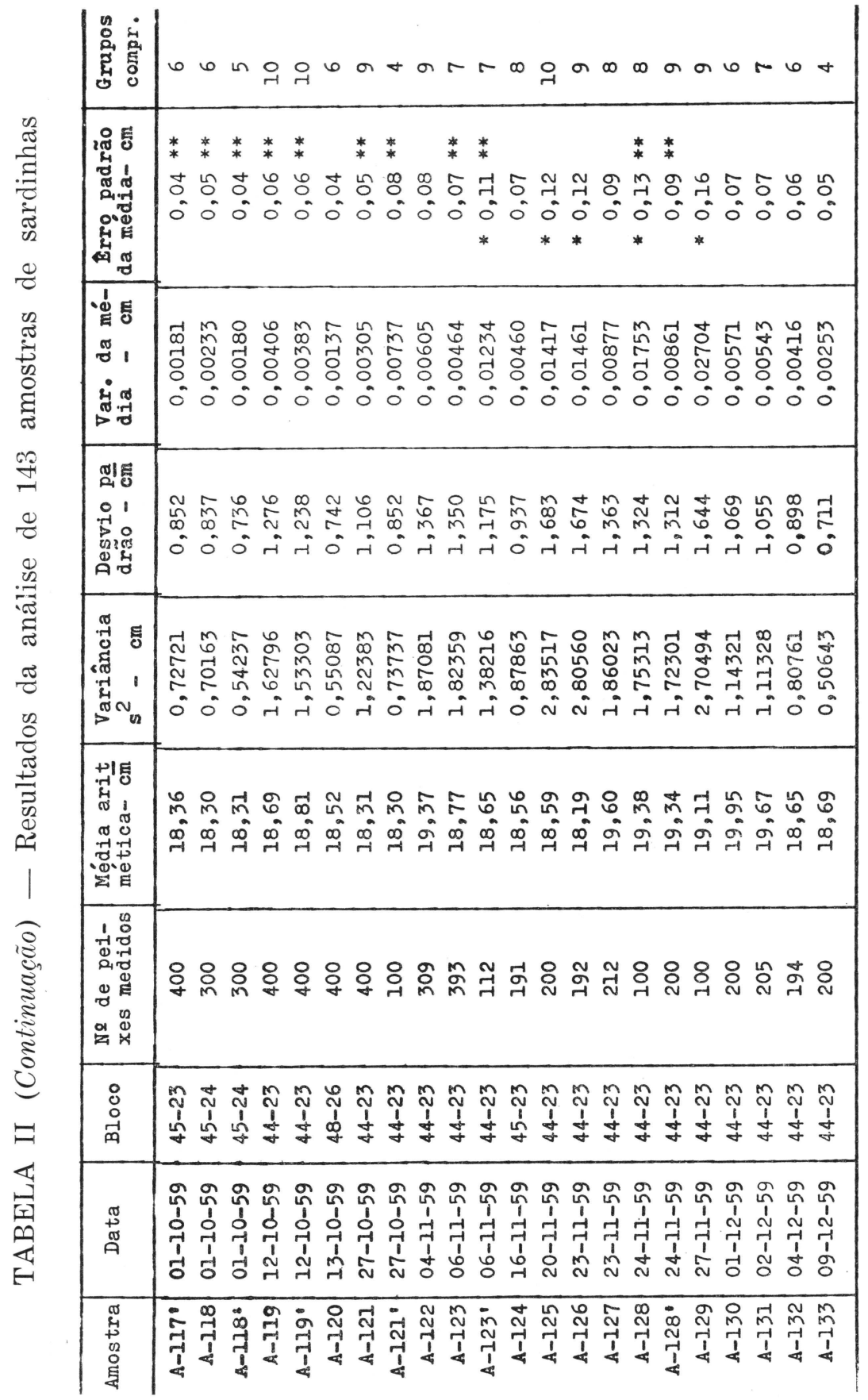


caria é suspensa. Projetava-se conseguir duas amostras semanais de sardinhas, por área de pesca, mas devido a êsses fatôres foi-nos difícil levá-lo a cabo com essa regularidade.

No desembarcadouro, as sardinhas são acondicionadas em caixas com capacidade para 60 quilos e em seguida levadas para pesagem no saguão do Entreposto.

Os medidores de peixes colocam uma caixa de sardinhas à parte, separam ao acaso, numa caixa vazia, um número $x$ de exemplares a ser medido; o restante é contado. $\mathrm{O}$ pêso exato dos peixes contidos na caixa é determinado.

Cada sardinha é colocada numa régua colorida de branco e amarelo, alternadamente, de meio em meio centímetro, e medida da ponta do focinho à extremidade da cauda, ligeiramente estendida (o procedimento é idêntico para as demais espécies citadas). Os comprimentos são medidos com aproximação de $0,5 \mathrm{~cm} \quad(16,00$ a $16,49=16,00$ ) e anotados numa ficha cujo modêlo se vê na Figura 2.

A separação, contagem e medição de sardinhas contidas numa caixa com capacidade para 60 quilos, realizadas por três pessoas, consomem cêrca de 30 a 40 minutos.

Conforme vão sendo medidas, quatro sardinhas de cada classe ou grupo de comprimento vão sendo separadas e colocadas num balde, as quais virão a constituir a amostra de laboratório. (Vide tópico I — Introdução.)

Tôdas as amostras obtidas, referentes às medições dos comprimentos, são analisadas.

A análise estatística dos dados anteriormente obtidos mostrará o limite de êrro que se pode aceitar para a obtenção de uma amostra representativa da parte dos peixes desembarcados da qual se fêz amostragem, que apresente variação mínima das estimativas e que seja isenta de vícios (ou bias).

O tamanho médio representa uma população e êle apresentará a máxima exatidão desde que as variáveis tenham distribuição normal.

Vários vícios são fàcilmente observáveis e podem ser eliminados. Assim:

1. Em virtude de haver diferenças na composição de comprimentos do peixe capturado e desembarcado quando se consideram aparelhos de pesca, locais e épocas, é conveniente tomar-se 
um grande número de amostras pequenas em vez de uma só, grande, de maneira a se eliminar ou reduzir essas diferenças.

2. Certos lances só trazem peixes de porte médio; outros, só peixes pequenos, numa mesma viagem. Nestes casos torna-se necessária a medição de um certo número de exemplares dessas duas categorias de tamanho e anotar o pêso total da captura correspondente.

3. Geralmente retira-se somente uma amostra por barco, no caso das sardinhas. Para se determinar se ela é representativa do total desembarcado pelo barco, podem-se retirar duas ou mais amostras (medições de comprimentos), de tamanhos iguais, de caixas diferentes, do mesmo barco; verificar se as diferenças são, ou não, significativas. Se as diferenças forem mínimas, bastará medir parte do peixe contido numa caixa; se forem significativas, precisar-se-á estudar um meio de retirar certo número de amostras pequenas, do mesmo barco, na tentativa de se eliminar ou reduzir essas diferenças.

4. A análise estatística só é válida se fôr aplicada em dados obtidos por amostragem feita ao acaso (random sampling), e não por seleção. Numa amostragem feita ao acaso todos os indivíduos da mesma população devem ter igual oportunidade de aparecer na amostra.

\section{IV - RESULTADOS}

$\mathrm{Na}$ análise dos dados de cada amostra as classes de meio centímetro foram agrupadas em classes de um centímetro (centímetro inferior, isto é, as classes de 16,00 a $16,99 \mathrm{~cm}$, por exemplo, foram agrupadas em $16,00 \mathrm{~cm}$ ). Nos dados das Tabelas I e II e Figura 3 não se levou em consideração o fator de correção de $0,5 \mathrm{~cm}$.

Os resultados da análise de 143 amostras de sardinhas (medições de comprimentos) são mostrados na Tabela II.

Êsses dados podem ser utilizados de vários modos, a fim de se estabelecer o número mínimo de peixes a serem medidos, de modo que a amostra a ser obtida seja representativa da população (captura de um barco) desembarcada. Assim, pode-se optar por uma das seguintes alternativas:

$1 .^{\mathrm{a}}$ - Construção de um gráfico colocando-se a variância da média no eixo das ordenadas e o número de peixes medidos no 
eixo das abscissas. A curva resultante tenderá a se aproximar de um L maiúsculo. Tão logo a curva do lado das abscissas tenda a ficar na horizontal, ao redor dêsse ponto estará localizado o número mínimo de peixes a serem medidos, e tomar amostra maior será anti-econômico.

$2 .^{a}$ - Para se obter certa exatidão contínua nos dados de medições dos comprimentos existe uma fórmula proposta por Pope (1956) a respeito da obtenção de amostras de arenques, que são Clupeidae como as sardinhas. Essa fórmula, segundo o referido autor, englobará a verdadeira média com $95 \%$ de probabilidades, sendo ela a seguinte:

$$
\overline{\mathrm{x}} \pm 2 \frac{\mathrm{s}}{\sqrt{\mathrm{n}}}
$$

Admitindo-se certo limite de êrro $(e)$, o valor requerido $(n)$ deve ser tal que

$$
\mathrm{e}=2 \frac{\mathrm{s}}{\sqrt{\frac{\mathrm{n}}{\sqrt{n}}}} \quad \cdot \mathrm{n}=\frac{4 \mathrm{~s}^{2}}{\mathrm{e}^{2}}
$$

Pela análise dos dados da Tabela II, a variância média é igual a $1,14 \mathrm{~cm}^{2}$, mas como os grupos de centímetros têm variado de 3 a 10 , achamos conveniente aumentá-la para $2,0 \mathrm{~cm}^{2}$, valor aproximado àquele encontrado quando há muitos grupos de comprimentos. A média aritmética está compreendida entre 16,5 e $19,5 \mathrm{~cm}$. Para se determinar o número de peixes necessário, com êrro de $1 \%$ na média, teríamos: $\mathrm{e}=0,165$ e 0,195. $\mathrm{O}$ valor de $e$ que dará o maior valor de $n$ será 0,165 . Portanto:

$$
\mathrm{n}=\frac{4 \times 2}{(0,165)^{2}}=\frac{8}{0,027225}=293
$$

$3 .^{a}$ - Construção de um gráfico colocando-se o êrro padrão da média no eixo das abscissas e o número de peixes medidos no eixo das ordenadas. Esta alternativa, por ser de rápida execução e apresentar resultados semelhantes à $2 .^{\mathrm{a}}$ alternativa, foi a que escolhemos e que é mostrada na Figura 3 e discutida nos parágrafos seguintes. 
 \\ V - DISCUSSÃO}

Um pequeno êrro deve ser aceito na determinação do número mínimo de peixes a serem medidos pela $3 .^{\mathrm{a}}$ alternativa. Vamos admitir que tôdas as amostras com êrro inferior a $0,1 \mathrm{~cm}$ sejam representativas da população (captura de um barco) desembarcada.

As amostras relativas aos meses de agôsto de 1958 a dezembro de 1959 foram colocadas num gráfico (Fig. 3), independentes da sua proveniência no que se refere a tempo, espaço e local da captura.

Os valores relativos a agôsto de 1958 (vide Tabela II) mostram-nos que em amostras com poucos grupos de comprimentos o êrro padrão da média é pequeno, conforme o tamanho da amostra. Sendo pequeno o tamanho da amostra e elevado o número de classes presentes, o êrro padrão da média tende a aumentar de valor. Nesse mês o número ideal está contido entre 200 e 300 , dependendo ainda do número de grupos presentes na amostra e que está indicado por símbolos, no gráfico, com a convenção respectiva.

Os valores referentes ao mês de outubro de 1958 tornam mais fácil a comparação das amostras. Três amostras, respectivamente com (3), (4) e (7) grupos de comprimentos e 462, 675 e 1.372 peixes medidos, apresentam o mesmo valor de êrro padrão da média. Significa que houve desperdício de tempo na medição de número elevado de sardinhas, além de 462, no caso. Certamente que reduzindo-se de 1.372 para 462 , haverá possibilidades de se aumentar o valor do êrro padrão da média, pois na primeira há (7) grupos de comprimentos e, na segunda, (3), mas isso não tem importância, desde que o êrro não ultrapasse $0,1 \mathrm{~cm}$, que é cinco vêzes maior que o encontrado para essas três amostras.

Outro mês em que nitidamente se percebe a desnecessidade de se medir muitos peixes é o referente a março de 1959, onde estão registradas quatro amostras com o mesmo número de grupos de comprimentos (6) e mesmo valor de êrro padrão da média. Essas quatro amostras correspondem a 419, 477, 482 e 555 peixes medidos. A medição de 400 peixes, por amostra, daria o mesmo resultado.

Pelo exame de todos os meses em conjunto fàcilmente se percebe que o tamanho da amostra que pode apresentar pequeno valor para o êrro padrão da média está ao redor de 300 peixes, independente do local, espaço e tempo de captura e número de grupos ou classes de comprimentos presentes na população desembarcada. 
Os valores de êrro padrão da média nos quais constam um asterisco (*) à esquerda são os que ultrapassaram o limite de êrro que resolvemos aceitar $(0,1 \mathrm{~cm})$.

Os pares de amostras com dois asteriscos (**) à direita (A-115 e A-115' ; A-116 e A-116' ; A-117 e A-117' ; A-118 e A-118' ; A-119 e A-119') correspondem a amostras de igual tamanho, respectivamente, retiradas do mesmo barco, mas provenientes de caixas diferentes; os resultados obtidos, para os pares, foram pràticamente os mesmos. Isso demonstra que, no caso da sardinha verdadeira, não há diferença sensível entre amostras retiradas de caixas diferentes, do mesmo barco, tanto no que se refere à média aritmética quanto à variância da média e êrro padrão da média. Portanto, podemos considerar essas amostras como sendo representativas da população (captura de um barco) desembarcada num dia particular e proveniente de certas áreas de pesca e de vários lances efetuados.

Já os pares de amostras A-121 e A-121'; A-123 e A-123'; A-128 e A-128', apresentam ligeira variação nos resultados, pois o tamanho da amostra dos pares não é o mesmo, embora os peixes que constituem as amostras A-121', A-123' e A-128 sejam parte daqueles que constituem as amostras A-121, A-123 e A-128'. Isso demonstra que as amostras retiradas da mesma caixa, porém, de tamanhos diferentes, apresentam sensíveis diferenças. No caso da amostra A-128, o tamanho dela precisa ser aumentado a fim de se diminuir o valor do êrro padrão da média; igualmente no caso da amostra A-123'. No caso da amostra A-121', por terem aparecido poucos grupos de comprimentos, o valor do êrro padrão da média não foi muito elevado e caiu dentro do limite de êrro que resolvemos aceitar.

As amostras A-116 e A-116' são provenientes de cardumes capturados em duas áreas de pesca diferentes. Para casos como êsse deve-se obter o total de peixe capturado em cada área e retirar-se uma amostra correspondente a cada área.

\section{VI - SUMMARY}

In this paper the author defines some statistical terms used, describes the sampling techniques adopted in the study of some fish, and quotes some problems concerning the determination of the composition of the stocks. The commercial fleet was utilized to sample the stocks of fish, in the assumption that the catch as landed on the fish market reflects the composition of the stocks in the sea. The paper is restricted to the evaluation of the length distribution of Sardine landed and for that purpose the Author examined 143 samples taken at random from August 1958 to December 1959. The analysis of those samples are shown in Table II and were plotted in Figure 3. The reliable sample size limit for Sardine was established as 300 , with the acceptance of an error of $0.1 \mathrm{~cm}$, considering the catch per boat as a population. 


\section{VII - AGRADECIMENTOS}

O Autor agradece a cooperação prestada pela Food and Agriculture Organization, na pessoa do Dr. Ian Dennis Richardson, orientador geral dos trabalhos de Biologia da Pesca no Brasil, no preparo destas considerações; ao Eng. Antônio Garcia Occhipinti, pelo esclarecimento de algumas dúvidas relacionadas com a Estatística; ao Serviço do Pescado, do Departamento da Produção Animal, da Secretaria da Agricultura do Estado de São Paulo e à Secção de Biologia da Pesca, do Instituto Oceanográfico, da USP, nas pessoas dos seus práticos de laboratório, que trabalham no Setor de Amostragem.

\section{VIII - BIBLIOGRAFIA}

Fowler, Henry W.

1941. A list of the fishes known from the coast of Brazil. Arq. Zool. do Est. S. Paulo, (III) :115-218.

Gulland, J. A.

1957. Sampling problems and methods in fisheries research. FAO Fish. Bull., X(4) :157-181.

Pope, J. A.

1956. An outline of sampling techniques. Rapp. et Pr.-Verb. des Réun., Vol. 140, Part I: Contributions to Special Scientific Meetings, 1954: Problems and methods of sampling fish populations, pp. 11-20.

Vieira, B. Borges, Carvalho, J. Paiva e outros.

1945. Anuário da Pesca Marítima no Estado de São Paulo - 1944. São Paulo, Dep. Prod. Animal, Div. Prot. e Prod. Peixes e Anim. Silvestres, Dir. Publ. Agr., Secret. da Agricultura, 122pp., 33 figs. 
Nomura, H. - Considerações sôbre amostragem...

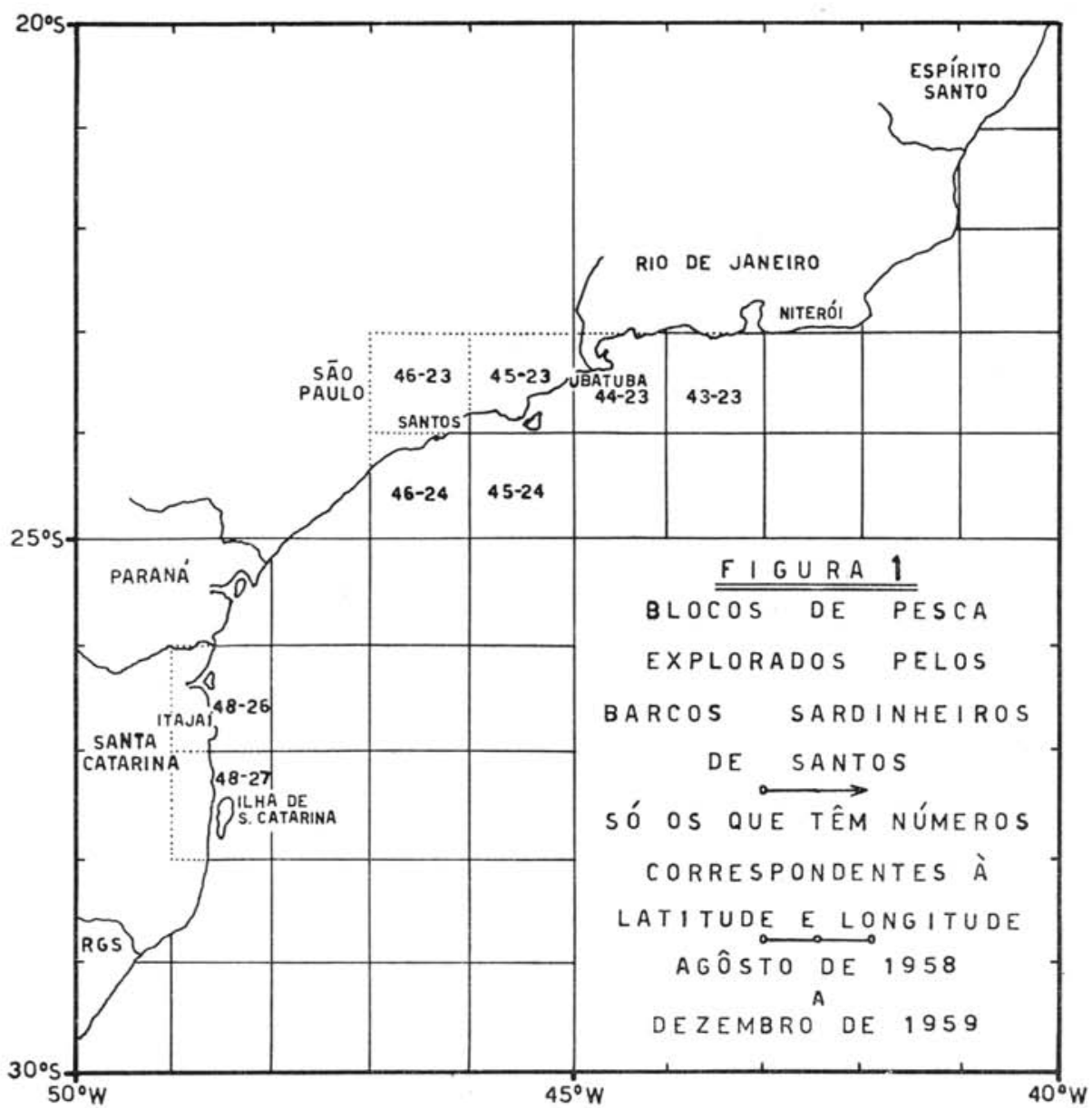


$-116-$

FIGURA 2

Modêlo de mapa para registro de amostras. 
Nomura, H. - Considerações sôbre amostragem...

FIGURA 2

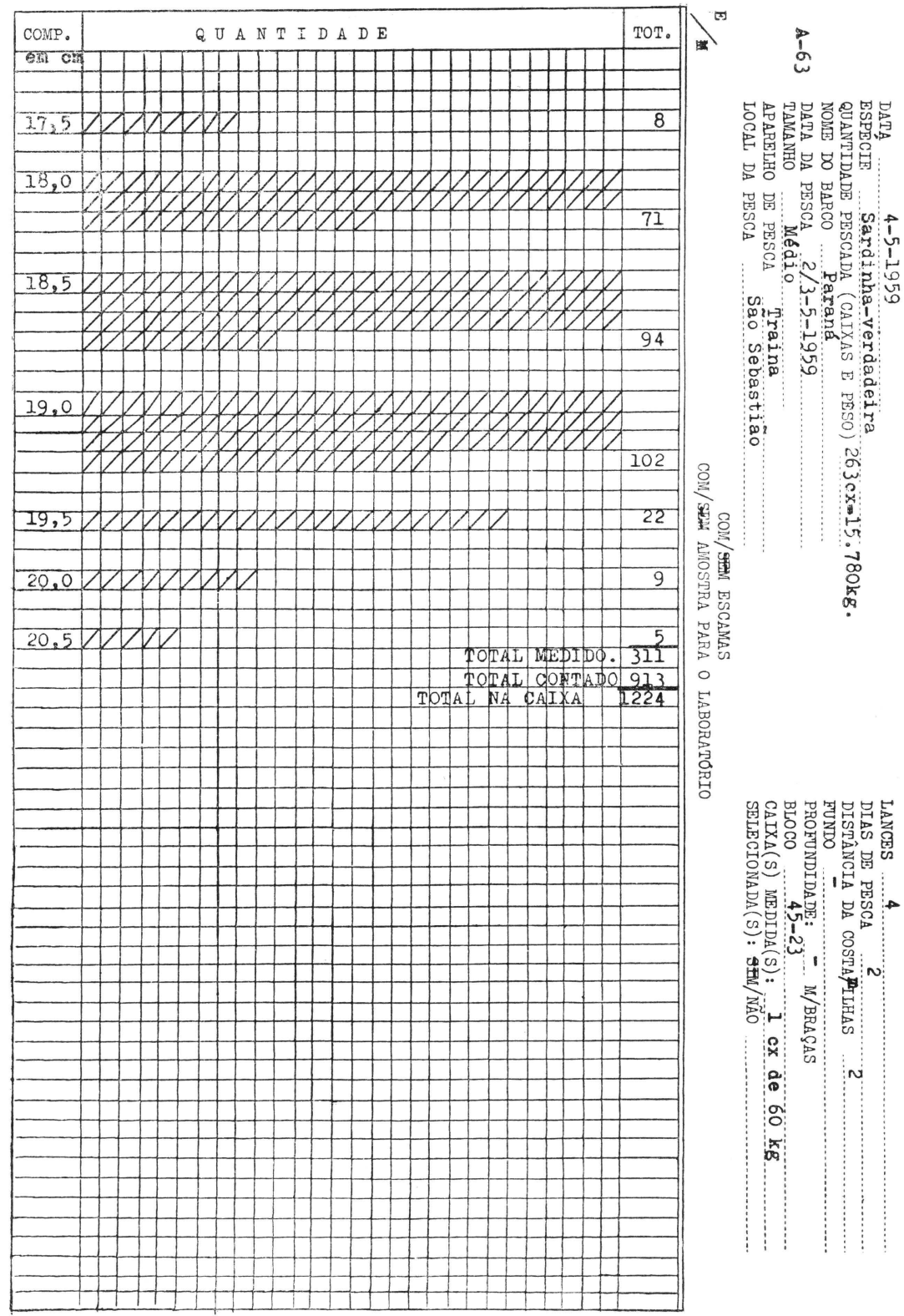


$-118-$

FIGURA 3

Relação entre êrro padrão da média e número de peixes medidos (143 amostras referentes aos meses de agôsto de 1958 a dezembro de 1959). 
Nomura, H. - Considerações sôbre amostragem...

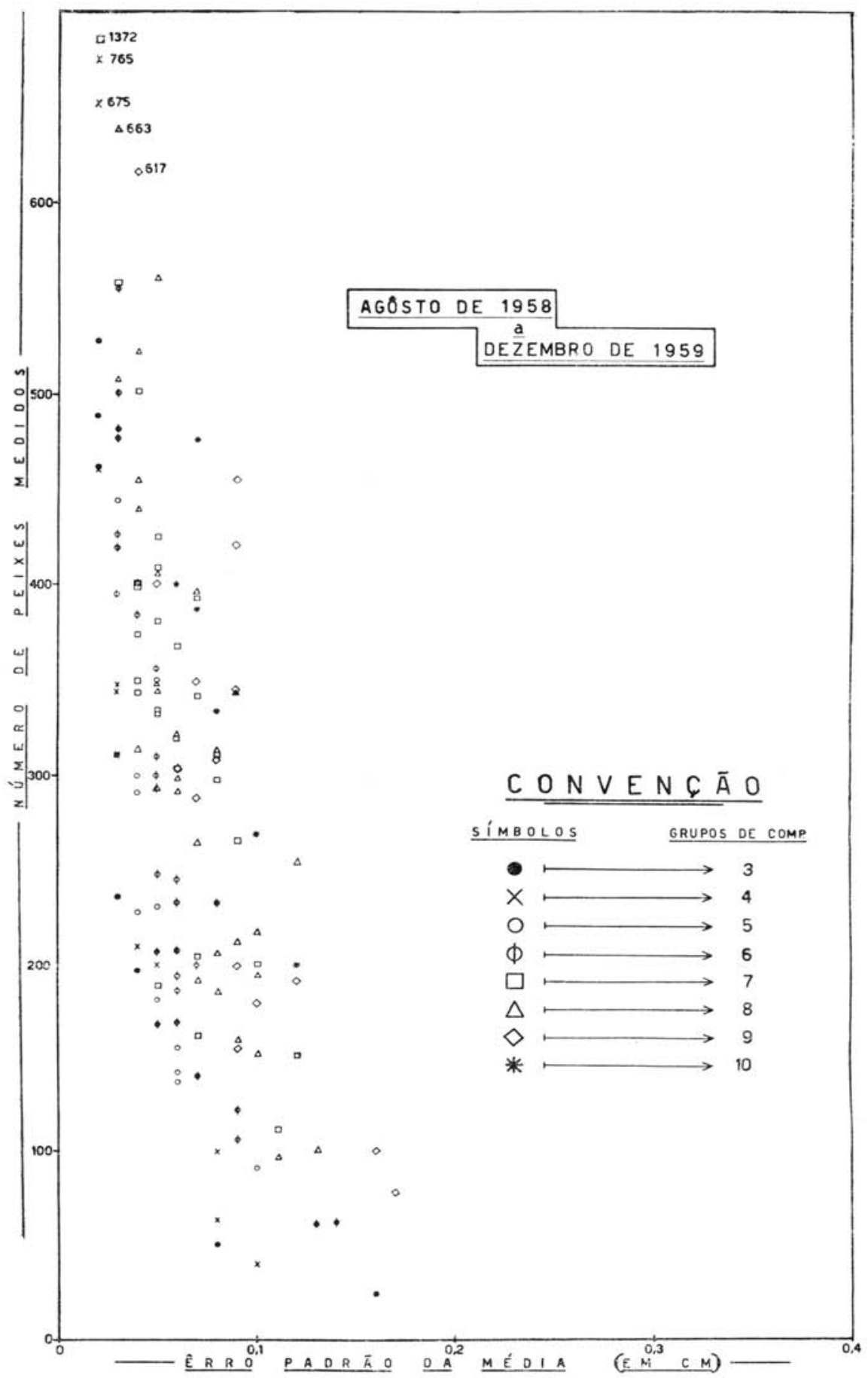

